\title{
EL PRINCIPADO DE ASTURIAS Y EL SURGIMIENTO DEL NACIONALISMO ESPAÑOL EN 1808
}

\author{
Carlos Javier Blanco Martín \\ Universidad de Oviedo
}

\begin{abstract}
Resumen: En nuestro trabajo pretendemos exponer unas reflexiones en torno al intento de construcción retrospectiva de una idea de Nación Española, partiendo de un viejo Imperio plurinacional, y una Monarquía de hegemonía castellana, tomando en cuenta el acontecimiento bélico-revolucionario de 1808: invasión napoleónica e insurrección popular. Para ello analizamos algunos de los pasos decisivos encaminados a la creación romántica de la "Nación", más o menos coincidente en el tiempo con la creación de otros mitos o conceptos de naciones en el contexto europeo. El paso del tiempo irá demostrando que este estallido brillante de una idea de "Nación Española" irá difuminándose por causa de una serie de acontecimientos dramáticos.
\end{abstract}

Palabras clave: Principado, Junta General, Nación, Nacionalismo español, Fueros, Estado plurinacional, Constitución Histórica del Principado

\section{The Principality of Asturias and the rise of Spanish nationalism in $\mathbf{1 8 0 8}$}

Abstract: We try to present some reflections on the attempt to build a sense of retrospective Spanish Nation, based on an old multinational empire, and monarchy Castilian hegemony, taking into account the military-revolutionary events of 1808: Napoleonic invasion and insurrection people. It looks at some of the decisive steps aimed at creating romantic "Nation", more or less coincident in time with the creation myths of other nations or concepts in the European context. The passage of time will demonstrate that this burst bright idea of "Spanish nation" will blur caused by a series of dramatic events.

Keywords: Principality, Asturian General Parliament, Nation, Spanish nationalism, Provincial Charters, multinational State, Asturian Historical Constitution

\section{INTRODUCCIÓN}

El año 1808 es una fecha que, a decir de muchos, representa el verdadero nacimiento de una Nación Española y que hoy, tras dos siglos, debería conmemorarse. La tesis que pide conmemorar tal efeméride suele venir avalada por el hecho mismo del Alzamiento popular que una parte significativa de los, hasta entonces, súbditos del Reino de España, protagonizaron contra las tropas francesas al mando de Napoleón. Sin que ello suponga negar la existencia de un "pueblo español" antes de tal acontecimiento rebelde, inicio de una larga y fatigosa Guerra de Independencia, hay cierta coincidencia en la historiografía oficial a la hora de señalar que ese "Pueblo" español con mayúsculas se vuelve autoconsciente entonces y sólo entonces, y que una supuesta Nación Española, más allá de haber sido previamente un conjunto de reinos y etnias unificadas bajo una misma Corona desde el siglo XVI, era un 
sujeto colectivo que salía finalmente a la luz espoleado por la humillación de una invasión extranjera, con abusos galos bien documentaos y una usurpación también extranjera de la corona hispana. Entre los escritores nacionalistas españoles de importancia, como Miguel de Unamuno, la efeméride de 1808 representa el inicio de una regeneración, un revulsivo, acaso un preanuncio de ese otro trauma de 1898:

El Dos de Mayo es en todos sentidos la fecha simbólica de nuestra regeneración, y son hechos palpitantes de contenido, el que Martínez Marina, el teorizante de las Cortes de Cádiz, creyera resucitar nuestra antigua teoría de las Cortes mientras insuflaba en ella los principios de la Revolución Francesa, proyectando en el pasado el ideal del porvenir de entonces... a nombre de la libertad patria, libertad del 89". [cit., en I. Fox, 1997: 117]

En este fragmento unamuniano se resume parte de la problemática que abordamos: 1808, y su puesta de largo de 1812, ¿es un corte operado sobre una cierta realidad hispana veteroliberal, fuerista, plurinacional y autonomista, en favor de una nueva entidad revolucionaria, o por el contrario el nuevo nacionalismo español que de aquí, de la francesada, surge, representa una continuidad respecto del proto-nacionalismo ya existente?

No somos historiadores, y dejamos el relato detallado de los hechos al especialista. En este trabajo nos ceñimos a una tarea estrictamente teórica e inevitablemente abstracta: dilucidar acerca de lo que podemos entender por Nación, y si de veras tal fecha de 1808 constituye de veras una efeméride a considerar como "Nacimiento de una Nación Española", acontecimiento que habría de suponer subitáneo y espoleta de ese otro poco después rubricado como Constitución de 1812, dada en Cádiz y todavía en plena guerra contra el francés. Problema abstracto nos traemos entre manos, pues, pero con no pocas consecuencias políticas a día de hoy. Son los días presentes, a dos siglos de aquellos hechos, en los que abundan posturas nacionalistas. Especialmente las de un nacionalismo español que, en gran medida reactivo ante los pujantes nacionalismos "periféricos" (vasco, catalán, gallego...) busca y rebusca en la historia con el ánimo de dorar e ilustrar sus posiciones. Si bien el nacionalismo español hegemónico fue, en nuestro siglo, una ideología conservadora -cuando no reaccionaria- muy dada a remontarse al pasado imperial de España en la época de los Austrias, también existe un relato liberal de corte nacionalista español, donde tales acontecimientos del "Viejo Régimen" se difuminan como en una suerte de proto-historia de la Nación Española, y entonces el relato épico de la "liberación" iniciada en 1808 cobra una importancia mayúscula. Tal y como Álvarez Junco [2001] describe de manera magnífica en su obra Mater Dolorosa, datar en esa fecha los orígenes de la Nación Española en el sentido moderno del término Nación, no podía por menos de ser un dato espléndidamente avalado en un sentido históricocomparativo. Esa fecha, comienzos del siglo XIX, es la época del Romanticismo. Como es conocido de forma sobrada, las invasiones napoleónicas significaron el disparo que despertó de su sueño a la mayoría de las naciones europeas. También en Inglaterra, Alemania, Italia y en otros pueblos más al oriente, la conciencia nacional se agita de su largo y larvado sueño, y de una forma netamente popular, violenta o insurreccional, supone el comienzo del fin de los imperios y de las viejas lealtades. 
Ninguna excepción fue este supuesto nacimiento, recalcamos que "moderno" de la Nación Española si se le entiende en el sentido convencional de la historiografía liberal, y que también hereda buena parte de la historia hecha desde la izquierda. La gesta de un pueblo que, en plena era romántica, lucha contra el invasor extranjero y frena su barbarie, cobrando de esa manera auténtica autoconciencia de ser algo más que una pléyade de súbditos y castas regidas por un mismo príncipe. Suena muy "romántico". Y en efecto, tan romántico fue este nuevo relato sobre los Orígenes de la Nación Española como otros alternativos que en aquella misma época circularon. De este jaez, romántico y acrítico, fue el relato ubicado en un tiempo mucho más remoto, según el cual la Nación Española habría nacido con la derrota de la morisma a cargo de Don Pelayo. Un caudillo de los ástures fue convertido, por obra los exegetas románticos (que llegan hasta hoy de la mano de los Menéndez Pidal, Menéndez Pelayo y los Sánchez Albornoz), en un godo, y en "el primer rey de España", vinculando así el Asturorum Regnum de forma harto fantástica, con el antiguo reino toledano de los visigodos. Aquel que, según las Crónicas, fue princeps de los ástures, y el iniciador, a lo sumo, del Reino Asturiano, pasa a convertirse en salvador y primer caudillo de una patria - una España- entonces inexistente.

En todo caso, el covadonguismo esto es, la ideología según la cual el Reino Asturiano y la revuelta de D. Pelayo y sus ástures en el siglo VIII fue el inicio de una Nación Española, no se extendió demasiado entre los autores españolistas más castellanófilos y ha sido más bien un mito eficaz a la hora de oscurecer la personalidad étnica y cultural del Reino Asturiano, después -en 1388convertido en Principado. Los filólogos e historiadores nacionalistas españoles, encabezados por Menéndez Pidal optaron por la singularidad germinal del minúsculo condado castellano, separado de la monarquía astur-leonesa y llamado a ser hegemónico en la península. Para ello, de forma pseudocientífica y racista, aludieron a un mayor "dinamismo" y "modernidad" de aquella Castilla primordial de base "germánica", ausente presuntamente en el Reino AsturLeonés. Como escribe Fox:

No hay por qué insistir en el hecho de el método positivista y la temática histórico-social, folclórica, y de psicología colectiva de Menéndez Pidal procede claramente del krausismo institucionista, tanto como la historiografía castellanófila a que ya hemos aludido. Concibe lo hispánico como una cultura unitaria cuyos principales elementos formativos son una Castilla innovadora y democrática que rompe con el feudalismo tradicional leonés. Fue Castilla, según él, la que ejerció la hegemonía decisiva en la (re)construcción de España. Asimismo existía un espíritu diferente entre los reinos peninsulares: un fondo ibérico en León y la mayor parte de Cataluña y Aragón, y un fondo cántabro-celtibérico en Castilla. Se destaca así la vitalidad renovadora castellana frente al tradicionalismo arcaico, romanizado, de León. Castilla se interpreta como la región más germanizada de la Península (interpretación en que insisten Costa, Ortega y Gasset, tanto como Menéndez Pidal y otros estudiosos del principio de siglo en la historia de España), menos romanizada, y pudo reunir a miembros de otras comunidades no romanizados: celtas, iberos, cántabros, godos. [I. Fox: 104-105].

Con estas categorías étnicas tan poco rigurosas se construyó el nacionalismo español de fin de siglo XIX, muy próximo al romanticismo más irracionalista, y 
muy ajeno a la verdad etnológica de aquellos núcleos cristianos peninsulares, muy poco "españoles", por cierto, en aquel lejano siglo VIII. El escaso siglo que a los krausistas, institucionistas, regeneracionistas y noventayochistas les separaba de la Guerra de la Independencia ante Napoleón, contexto en el que se ubica una Constitución liberal, la de 1812, y una refundación del estado español, no pareció muy atractivo a estos escritores y eruditos. Mayor pedigrí de "españolidad" seguía proporcionado la especulación sobre la sangre goda y las virtudes del Cid Campeador.

Ciertamente, la elección de fechas fundacionales ha sido una labor ideológica y de interés netamente político. Las circunstancias dialécticas del momento imponen una fecha u otra como la más conveniente. En el siglo XIX no faltaron momentos en los que África -mejor dicho, unos territorios del actual Marruecos- representaban la tumba para miles de soldados españoles, y el islam quedaba grabado en las conciencias cristianas como paradigma de la alteridad religiosa, haciendo así de la Reconquista un modelo de cruzada nacional contra el infiel. Nada pareció importar entonces que, a parte de Asturias, otros núcleos norteños también hubieran repelido a la morisma (ahora, en la España de las Autonomías, ese dato sí importa mucho más). De igual manera, cuando se inventa un "mito fundacional", poco puede interesar al Poder promotor del mismo el pequeño "detalle" de que ese tal Pelayo quizá hubiera sido alguien inicialmente afín a los invasores, o que los ástures que lo secundaron, igual que sus aliados y hermanos cántabros, muy probablemente eran paganos en su mayor parte, en tanto en cuanto no recibieron el influjo de los refugiados cristianos que veían del sur. Pero si en lugar del mito covadonguista obcecado en la búsqueda de una cuna de la Nación Española, apelamos a otros, quizá no tan lejanos en el tiempo, pero igualmente muy queridos por la historiografía tradicionalista, a saber, el mito del Casorio de Isabel y Fernando, un mínimo conocimiento de los hechos arroja por tierra la labor "unificadora" de aquellos "Reyes Católicos". La Corona de Aragón y la de Castilla conservaron largo tiempo su personalidad jurídico-política independiente, por no hablar de la anexionada Navarra. El azar y las maniobras de ciertos protagonistas del momento quisieron que las dos grandes Coronas, al menos, la castellana y la aragonesa, no se volvieran a desunir y seguir sendas independientes. Para más señas, la estructura interna de estas dos grandes Coronas era sumamente compleja y plural. Por razones históricas y enraizadas en el derecho medieval, los territorios se iban incorporando a una Corona sin perder por ello su autonomía legislativa, sus cámaras representativas e incluso su "pase foral" ante las decisiones regias. Este régimen que yo llamaría paleo-autonómico (para diferenciarlo del Estado de las Autonomías hoy vigente desde la promulgación de la constitución de 1978) o incluso "paleo-federal", era una realidad en el Antiguo Régimen, y la tradición historiográfica liberal -muy centralista- ha tendido a oscurecerla. La supuesta nación que emerge, con ciertos tintes épicos y melodramáticos en 1808, para consagrarse legítimamente en 1812, era todavía a esas alturas, un conglomerado de territorios asimétricamente vinculadas a la Corona Española1. Es cierto que los fueros de la Corona de Aragón habían sido

\footnotetext{
${ }^{1}$ Se puede sostener, siguiendo a Inman Fox [1997: p. 55] que hasta finales del siglo XIX no se desarrolló un nacionalismo español, de corte castellanófilo o castellanocéntrico, que fue detonante a su vez del auge de los nacionalismos o-como entonces más bien se decía, "regionalismos" periféricos. Pese al "brillante" nacimiento de la España en sentido moderno y
} 
suprimidos en 1712 tras la toma de postura de estos territorios por el partido austracista en la Guerra de Secesión. Una Corona, la Aragonesa, que había sido modelo de paleo-autonomismo hasta su unión con Castilla: el Principado Catalán, el Reino Aragonés propiamente dicho, el Reino de Valencia, y (en este caso con algún intervalo de independencia) el Reino de Mallorca. Suele recordarse que nuestra actual Constitución de 1978, a través de la Disposición Adicional Primera, reconoce los derechos históricos para las provincias vascas, y Navarra. Los fueros vascos fueron suprimidos definitivamente en 1876, tras sucesivos recortes efectuados desde Madrid, y después de las Guerras Carlistas. El fuerismo vasco-navarro, como es sabido, fue el acicate del movimiento carlista y la gran alternativa -beligerante- al modelo de Estado liberal español que supuestamente emanaría de la insurrección antinapoleónica que hoy nos toca comentar. A pesar de ello, hay que aclarar de inmediato que el carlismo fue un reto y un proyecto para toda España o, como los carlistas hubieran preferido decir, para las Españas. Más allá de la defensa de unos fueros -entendidos unilateralmente como "privilegios"- o más allá de la consabida cuestión dinástica, el carlismo fue, en palabras del propio Karl Marx, el movimiento de raigambre popular de más trascendencia dentro de las rebeliones pre-industriales de Europa. Afectó más o menos a toda la mitad norte del Reino de España, y no sólo gozó de aceptación en las provincias euskaldunas (a partir de cuyo carlismo surgió el nacionalismo vasco como uno de sus derivados, con S. Arana, como es sabido) sino en otras zonas2. Más allá de la pequeña nobleza y del clero, también contó con muchos seguidores entre el campesinado, los profesionales y artesanos de clase media, etc. Un nuevo modelo de estado, más descentralizado (el paleoautonomismo que fracasó en el siglo XIX y buena parte del XX), una alternativa al "progresismo" de corte jacobino, laicista y en el fondo importado, era la base de su ideología, no siempre y en todo aspecto de signo "reaccionario" como los historiadores liberales nos han querido decir. La estructura pre-liberal del Reino Castellano contaba con otras asambleas que, con una existencia más o menos lánguida, a

liberal, con la revolución o alzamiento de 1808 (en rigor, una suma de alzamientos por parte de Juntas locales y regionales que fueron confluyendo en un sistema constituyente, el gaditano de 1812), no fue hasta mucho tiempo después cuando se instituyeron unos símbolos nacionales unitarios, acordes con un nacionalismo hispánico normalmente de signo liberal, que sólo con mucho más retraso aún serían aceptados por los sectores tradicionalistas, católicos e incluso ultras, y que serán asumidos ya plenamente y sin reticencias en pleno siglo $X X$, en el bando franquista, a pesar de su origen jacobino-liberal. Como dice I. Fox '[1997:55]: "A pesar de la actividad de tipo nacionalista que venimos estudiando [Fox se refiere a la invención del nacionalismo español a partir de los regeneracionistas, los krausistas y krauso-positivistas, de finales del s. XIX], la verdad es que España llegó tarde a la socialización o "nacionalización" del pueblo. No se estableció, por ejemplo, un sistema nacional de escolarización pública hasta la segunda mitad del siglo (y aun entonces era poco eficaz); y el servicio militar no fue unversal hasta 1911. En cuanto a símbolos, no existió una bandera nacional hasta 1843, ni un himno nacional hasta el siglo XX, y casi no había monumentos nacionales a principios de siglo".

2 Marx, mucho más que los "marxistas" que le siguieron, supo ver la raigambre popular del carlismo, en modo alguno de tinte elitista o nobiliario. El carlismo del siglo XIX no fue un movimiento nacionalista, pese a su defensa de los fueros y antiguas territorialidades, no deja de ser un proyecto para el conjunto de España o las "Españas". La historiografía liberal triunfante- cargó las tintas sobre el cariz ultraclerical, dinástico y absolutista del movimiento carlista, no queriendo ver en él un proyecto igualmente federalizante para España, aunque alternativo al de los republicanos. También, a excepción del aranismo, hay que retirar cualquier matiz racista o defensor de privilegios. Los viejos fueros eran el patrimonio verdaderamente constitucional que en sentido histórico poseían los reinos de España. 
causa de los sucesivos recortes sufridos con el auge del absolutismo a partir del siglo XVII, aún conservaban su plena autonomía soberana. Entre las Juntas norteñas, la Junta General del Principado no contaba con menos atribuciones que sus homólogas vasco-navarras. Surgida, si no antes, en el mismo momento en que se creó la institución del Principado de Asturias, en una maniobra por parte del rey castellano don Juan de apoderarse de este dominio cuya nobleza era por entonces abiertamente separatista, la Junta General del Principado bien pudo haber sido la sucesora directa de la Asamblea o Concilio que el propio país ástur tuviera desde los tiempos en que fue reino independiente, o territorio autónomo dentro de la monarquía sucesora, la del reino de León, al extenderse más hacia el sur, hacia la Meseta, sus dominios y quedar trasladada la Corte Regia de Oviedo a León. Con todo, y especulaciones a parte, es a partir de 1388 el momento en que la Junta General aparece como "Constitución" del país ástur, en palabras de sus más insignes comentaristas (Jovellanos, Caveda y Nava), y "hermanamiento de todos los concejos del Principado" [J. Caveda y Nava, y otros, 1989 ; F. Tuero Bertrand, 1978] 3. La amplitud de sus competencias fue viéndose mermada, desde un periodo de esplendor en tiempo de los Reyes Católicos, con la creación de las Audiencias en tiempos borbónicos y otros cargos de cuño centralista. Merece que recordemos esta Institución asturiana, tan solo recuperada con la proclamación de la autonomía del Principado de Asturias en 1981, por su papel destacado en la insurrección de 1808 contra el invasor francés. De todas las Juntas "provinciales" o "revolucionarias" que se alzaron en el Reino de España para oponerse a los ejércitos y planes de Napoleón, a raíz de los acontecimientos de Madrid en el mes de mayo, consta que fue la Junta del Principado la primera en alzarse en armas y declarar la guerra. Para ello, y en aparente contradicción con su autoproclamado carácter "revolucionario", hemos de recordar que dicha Junta asturiana reclamó su más ancestral e inveterada soberanía en alusión a que, estando vacante el trono del Rey de España, por la usurpación tramada por el Emperador, la soberanía absoluta de Asturias recaía, en tales graves circunstancias, en el órgano representativo tradicional de ese país. En tal sentido, la Junta -al mismo tiempo revolucionaria y tradicional- envió embajadores a Inglaterra, declara a Napoleón la guerra -en calidad de soberana y sin contar con los insurrectos de Madrid o de ninguna otra parte y envía agentes a las provincias cercanas para

\footnotetext{
3 "La Junta General era un cuerpo político provincial, una asamblea representativa de todos los concejos de la región, deliberante y consultiva, encargada de velar por los intereses públicos del Principado, y a través de la cual participaban los asturianos en la gestión y administración de sus asuntos, con sometimiento a lo dispuesto en las leyes generales del Reino". [Tuero, p. 19]. El profesor Tuero Bertrand tendía a rebajar el carácter foral y soberano de la Junta General del Principado, pero otro tratadista de la misma, D. Miguel de la Villa, la considera del todo análoga a las Juntas generales de las tres provincias vascas, incluso en lo referente al uso o pase foral. Según De la Villa: "Asturias no tuvo esta facultad, al menos del modo absoluto con que la disfrutaron las otras provincias; podía, sí, rechazar una disposición que atacara directa é indirectamente sus frnaquicias y libertades, suplicaba se derogasen las leyes atentatorias á sus fueros, negaba los servicios que se la pidieran, cuando no estaban conformes con las costumbres y tradiciones del país ...) [J. Caveda y Nava y otros, p. 137]. También la Junta asturiana, no menos que las vascas tuvo derecho a legislar, o al menos “...obró muchas veces como si tuviera este derecho de legislar, reformó en diferentes ocasiones las ordenanzas dadas por el Soberano, las llegó casi a anular, formando otras enteramente nuevas " [José Caveda y Nava y otros, p. 138]
} 
instigar en ellas la rebelión, creándose de inmediato un ejército a expensas de la propia Junta.

En palabras de Don Miguel de la Villa, uno de los historiadores de la Junta General del Principado, escritas éstas en 1909:

Apenas se supo en Oviedo en 9 de Mayo los sangrientos sucesos del día 2, ocurridos en Madrid, cuando la Junta reunida en aquella ocasión en la Sala Capitular de la Catedral, oyendo el grito de entusiasmo de la ciudad entera, declara la guerra á Napoleón, por sí misma, y envía Embajadores á Inglaterra, firma la paz con aquella potencia y negocia un tratado de alianza entre el Reino unido y el Principado asturiano. Decreta en uso de su soberanía el levantamiento de un ejército, que en breve sale á campaña, no sin que antes envíe la Junta individuos de su seno á sublevar las provincias colindantes, auxiliándolas con armas y dinero.

Ocurren los sucesos del día 25 y el 28, ratifícanse los acuerdos tomados, se nombraron un Capitán general y varios tenientes generales y gobernadores militares, Ministros de Hacienda, Gracia y Justicia, Estado y Guerra, y durante algún tiempo fué Asturias completamente independiente del resto de España [esta última cursiva es nuestra], pero lejos de ser funesta a la Patria española, la fué tan útil, que de allí de donde ya había salido triunfante la libertad en la reconquista de la España visigoda, del mismo lugar salió el grito que levantó á los nacionales, salvándoles del poder de Napoleón. [ J. Caveda y Nava y otros, 1989: 115].

Muchos de los que combatieron en España al francés lo hicieron en nombre de ciertos ideales liberales, en gran medida importados de la oleada revolucionaria que surgió en 1789. Pero no es menos cierto que muchos otros lo hicieron en nombre de una Tradición. Y esta Tradición no era de signo exclusivamente reaccionario, teocrático, absolutista, sino la tradición específicamente hispana o ibérica- que arranca de la Alta Edad Media y que hasta su decadencia bajo los Austrias reivindica para los reinos hispanos una "Constitución Histórica" (Jovellanos), con sus propios fueros y libertades, como se deja ver en las provincias norteñas (Asturias, Navarra, Vascongadas) o en el espíritu liberal avant la lettre de los Comuneros de Castilla. La conducta de la Junta General del Principado en 1808 es muy significativa al respecto: una Revolución antinapeoleónica en nombre de una ancestral tradición "constitucional" y una vieja legitimidad histórica.4

\section{NACIÓN Y NACIONALISMO}

Hobsbawn nos recuerda que el nacionalismo, tal y como hoy lo entendemos, es un fenómeno histórico bien reciente, del mismo modo que es reciente la acepción moderna de la palabra "Nación". Como término, "Nación" significa

\footnotetext{
${ }^{4}$ Muy interesante es lo que escribe F. Carantoña en lo que se refiere a la conducta de la Junta asturiana: "... Asturias no va aconsolidar una verdadera Junta revolucionaria, sino que el poder acabará siendo asumido por la Junta General del Principado. Este protagonismo de un órgano de Gobierno del Antiguo Régimen dará características peculiares al proceso asturiano (...) por la asunción por parte de este organismo de la idea de que había recuperado un poder que históricamente le correspondía y que había sido cercenado por la administración borbónica. Por esta razón, la Junta va a legislar con mayor libertad que las de otras regiones y sólo va aceder su poder en mayo de 1808 ante una intervención militar." [Carantoña, 1989: 73].
} 
hoy, aproximadamente, una comunidad humana más o menos homogénea en lo lingüístico y en lo etnológico que, asentada sobre un territorio igualmente definido en sus límites y regida por autoridad única y común. Es decir, en los últimos cien años, la correlación entre Nación y Estado es muy sólida, y en aquellos casos en los que la Nación carecía de Estado, bien por encontrase sumergida en un Estado más grande, o bien por sufrir un reparto en dos o más unidades estatales ajenas, el Nacionalismo de la última centuria representa siempre una aspiración a formar un Estado coincidente con la Nacionalidad. Pues bien, en los diccionarios de las distintas lenguas europeas, incluyendo el de la RAE, sólo observamos este sentido marcadamente político (el de una vocación estatal para toda Nación que no hubiera alcanzado dicho status) a partir de 1890, y muy especialmente hasta bien entrado el siglo XX [E. Hobsbawm, 1991: 24] 5. Antes, "Nación" en diversas lenguas significaba simplemente "lugar de procedencia", "origen" de una persona o colectividad, con abstracción hecha de la entidad estatal en la que esa persona o colectivo se encontrase. Refiriéndonos al caso de España, no cabe la menor duda de que el gentilicio "españoles" es muy anterior a la insurrección de 1808 en la que "el pueblo", más que un "Reino de España" por cierto usurpado, cobra conciencia de sí ante un ejército extranjero de ocupación. Por otro lado, no es menos cierto que un Estado correspondiente a ese Reino de España que acababa de ser dañado en su soberanía a ojos vista, e incorporado a los planes imperiales de Napoleón, había sido uno de los primeros Estados de corte imperialista y con vocación centralizadora, de la Europa Moderna. La tendencia imperial-colonialista (expansiva) y centralizadora (en los terrenos etnolingüístico y administrativo) de la Monarquía Hispana fue de todo punto pionera y, después, homóloga a la de los otros reinos absolutos de la Europa Moderna (Inglaterra, Francia). En la fecha en que un "pueblo" más que un "Reino", habitante en los territorios hispanos, se levanta ante el francés en 1808, ya existían cinco siglos (no todos ellos muy brillantes) de existencia unificada por vía regia. Algunas instituciones, como la Inquisición o la Santa Hermandad, fueron de un carácter inequívocamente centralizador, y su radio de acción sobrevolaba las antiguas franquicias y libertades que los diversos reinos hispanos medievales habían heredado. Esto aconteció desde finales del siglo $\mathrm{XV}$, pero con todo las tendencias absolutistas y centralizadoras de los austriacos y los validos fueron más en la línea de la política real, de la política ejecutiva de los hechos consumados, aun cuando se respetaran las antiguas formas de origen medieval, que recordaban sin cesar la plurinacionalidad de la Monarquía Hispana. La hegemonía demográfica y económica del Reino Castellano fue la materia sobre la que los reyes Habsburgo asentaron una

\footnotetext{
${ }^{5}$ El nacionalismo stricto sensu es un fenómeno muy reciente. En el diccionario de la RAE no se encuentra una definición definitiva de nación como "conjunto de personas de un mismo origen étnico y que generalmente hablan un mismo idioma y tienen una tradición común". Es evidente, que antes de nuestra fecha de referencia, 1808, existe -sobre todo en Madrid y en Castilla, un protonacionalismo español, en el sentido que le da Hobsbawm en el libro que citamos. El protonacionalismo está muy vinculado a la conciencia que un pueblo posee de haber pertenecido a una misma entidad política de forma estable o duradera [E. Hobsbawm, 1991: 55-88]. El protonacionalismo, netamente popular, es la base más firme (incluso por encima de la lengua o la etnicidad) de eso que se da en llamar "nación histórica". En el caso de España, poliétnica y políglota desde hacía siglos, la conciencia nacional, el "españolismo" es más bien de este tipo. Los famosos "500 años de historia común" son invocados sin cesar por muchos de sus voceros. Solo en décadas recientes la "pureza de la sangre", presuntamente goda, ha dejado de invocarse en Castilla o en España.
} 
política cada vez más castellanocéntrica, en cuanto al uso de su idioma como lingua franca y oficial. El otro plano de análisis es el normativo-jurídico, en el cual el arquetipo de las nuevas normas fundamentales del Reino se asentó sobre el castellano y sobre el de las otras coronas. Con todo, la decidida reforma institucional en un sentido absolutista y centralizador, a imitación del modelo francés, aconteció con el cambio dinástico y alcanzó su punto culminante justo en el momento en que los ejércitos de Napoleón fueron expulsados de España y las oleadas de liberalismo europeo llegaron a la península.

El comienzo para la refundación de una España como Nación moderna en el sentido liberal, fue, al decir de Álvarez Junco de lo más prometedor [J. Álvarez Junco, 2001]. Un "pueblo", tras el madrileño, todos los otros pueblos y naciones del usurpado Reino de España, un colectivo plural que reaccionó de forma unida y solidaria ante la humillación extranjera: asturianos, aragoneses, castellanos, catalanes... Todos se sintieron pisoteados en algo "muy suyo", no obstante los cinco siglos previos de existencia plurinacional y de centralismo creciente y, en ocasiones, aplastante para con las diferencias. Un comienzo así haría las delicias del jacobino-liberal en su relato de una "refundación de España". Y de hecho se intentó una refundación con la Constitución Gaditana de 1812, si bien los tintes jacobino-revolucionarios de origen francés fueron muy rebajados desde el principio. Algunos prohombres de la época, por ejemplo Jovellanos, siempre habían optado por la versión más moderada, prerevolucionaria, del liberalismo inglés: mejor Locke que Robespierre. En aquel entonces, la Monarquía Parlamentaria británica podría ser vista como buen arquetipo de plurinacionalidad unificada bajo una sola Corona, activamente comprometida con la defensa de la religión así como con las tradiciones y usos locales de sus súbditos. Con todo, el suelo hispano no parece haber sido muy proclive al moderantismo que el insigne ilustrado asturiano profesaba.

Ese violento renacer de una nación española, bien definida ante fuerzas invasoras, que auguraba un prometedor proceso de homogeneización y unidad, habida cuenta que los pueblos hermanos suelen fundirse más ante enemigos externos, fue un completo fracaso. Tras la expulsión del francés, el Reino de España careció de amenazas extranjeras significativas hasta la guerra contra los Estados Unidos que dio en fracaso estrepitoso de 1898. Las aventuras coloniales, pese a lo sangrientas que resultaron y lo frustrantes que acabaron siendo a la larga, no fueron sino empresas artificialmente buscadas para saciar un ansia psicológica de "primacía" externa de esa modesta potencia europea de segundo orden que era España. La auténtica faz de una nación fracasada, al menos desde la óptica liberal y jacobina de un estado centralizado y moderno, la ofrece el estado casi permanente de guerra civil de todo el siglo XIX. Las guerras carlistas son contiendas civiles específicamente hispanas, que si bien pueden parangonarse hasta cierto punto con otros movimientos campesinos o tradicionalistas europeos, ponen de manifiesto lo complicado que fue en este Reino conciliar al pueblo en torno a un proyecto compartido por la mayoría. Los liberales, siguiendo aquí el análisis de Álvarez Junco, no se quedaron cortos en "extremismo" a la hora de suprimir tradiciones y derechos en aras de un nuevo Estado de corte claramente centralista y con tendencias laicas. Por otra parte, las sucesivas medidas administrativas, desamortizadoras, y, en suma, "nacionalizadoras" solo satisfacían a una parte 
de la sociedad, generalmente la nobleza cercana a la monarquía y a una burguesía beneficiada por la cercanía política a ella y a los poderosos, que daría pie al sistema conocido como caciquismo. La pequeña nobleza rural, y el campesinado "libre" de las regiones norteñas no podían simpatizar con estos nuevos ricos que, dándoselas de modernizadores, se permitían el lujo de atentar contra la Iglesia y las más inveteradas tradiciones. En cierto modo, los acontecimientos de 1808 preludiaron todo el siglo XIX hasta el desastre de Cuba de 1898: guerra intestina en una Nación incapaz de asentarse como tal en el concierto de las demás naciones-estado europeas "burguesas". Salvando el dato de la invasión extranjera, ante la que todo un pueblo "despierta" su conciencia nacional, muchos otros elementos de nuestra efeméride parecen preludiar lo que fue el siglo XIX, y buena parte del XX: una guerra civil permanente, una lucha fratricida. En efecto, la guerra al francés fue en aquel año la guerra al español que había sido amigo del francés. El afrancesado, más allá de la tradicional etiqueta de "traidor", en el sentido estricto de colaborador con el enemigo, era el personaje portador de ideas nuevas que al calor de la Revolución de 1789, pretendía modernizar un país que, en los más diversos órdenes, permanecía atrasado y aislado. La crueldad de un supuesto "pueblo espontáneo" se cebó sobre este tipo de persona que no era necesariamente un colaboracionista en el sentido político-militar, sino un intelectual con afán modernizador. La llamada a la rebelión de 1808, como otras insurrecciones de la historia, no pudo ser tan espontánea como se dijo, y la prédica desde los púlpitos y el discurso incendiario de los sectores más ultramontanos de la Iglesia tuvo mucho que ver con ello. ¿Fue este año el del nacimiento de un "pueblo" español? El análisis de las proclamas puede revelar que muchos salieron a matar franceses por afán de salvar la Tradición, vale decir, la Fe Católica, amenazada por un extranjero impío. El designador exacto del insurrecto español de 1808 fue el de "Católico", antes que "Español". Lo mismo, como leemos en Mater Dolorosa, cabe decir de la defensa de la verdadera Monarquía Hispana. Quienes se enfrentaron entonces al Emperador lo hacían en nombre del Rey, de una Monarquía Católica como la española que debía seguir existiendo como garante de la verdadera Fe. Dicho de otro modo, todavía en el alzamiento de 1808, y se puede decir que en todo el siglo XIX, lo que obraba como motivo impulsor y afán restaurador de los insurrectos y guerrilleros españoles fue el Altar y el Trono, y no una supuesta Nación Española que, más tarde, sólo después de 1812 y tras la férula de los políticos liberales, trataría de impulsarse como idea.

La persecución de los afrancesados, la existencia de un clero ultramontano e incluso feroz, la fuerte identificación de las masas activas con respecto a la Monarquía, todavía investida con atributos casi medievales de Defensora del Credo (Tridentino), y la Iglesia, fueron hechos que se manifestaron en la fecha que conmemoramos. Y lo que parecía ser un comienzo ideal para un estadonación "canónico" en el sentido burgués y colonialista, el sentido del siglo XIX, fueron en el Reino de España, precisamente, el obstáculo objetivo para la viabilidad de ese sentido nacional coincidente con un estado-canónico como el francés o el inglés. También éstos partían de una situación poli-nacional. E. J. Hobsbawn [1991] nos recuerda como en la antesala de la revolución de 1789, sólo el 50 por 100 de los franceses hablaban el idioma que luego fue único y oficial. Por su parte, el Reino Unido, tras una larga política de asimilación de los países célticos anexionados a Inglaterra, aún se daba un importante 
bilingüismo (lenguas gaélicas/inglés) o monolongüismo en lenguas gaélicas, en ellos, y las diferencias étnicas y religiosas de los países célticos antaño soberanos (Irlanda, Escocia, Gales). El jacobinismo francés, es decir, el modelo de ciudadanía homogénea para un estado-nación postrevolucionario, no tuvo nada que ver con el caso británico, más asemejado a la tradición hispana del Antiguo Régimen: una nación (Castilla aquí, Inglaterra allá) impone su hegemonía lingüística, económica, política, militar a las demás naciones, que se marginan por diversos medios, pero a las que se sigue reconociendo como "naciones de propio derecho" aunque integradas en una Corona única. De ahí que se conservaran en el Reino de España las Juntas norteñas hasta bien entrado el siglo XIX: la Junta General del Principado no se disolvió hasta 1835, en el apogeo de la ideología liberal en la Corte madrileña. Las juntas vascas y navarras duraron más tiempo, en relación con las guerras carlistas. El modelo del Antiguo Régimen español también presenta parentescos con los de otras monarquías plurinacionales, como fue el Imperio Austro-Húngaro, que persistió hasta el fin de la I Guerra Mundial. En esta monarquía, la hegemonía cultural y política germanófona de los austriacos es muy matizable ante el número ingente de nacionalidades integrantes de aquel estado, mucho más dispares entre sí en los aspectos étnicos, religiosos, idiomáticos. Tales estados monárquicos plurinacionales, aunque siempre cuenten con una nacionalidad hegemónica, suelen reconocer un principio de co-gobierno, o de representación popular local, provincial o regional históricamente legitimida y sancionada por los monarcas. En el Reino español, el liberalismo jacobino de origen francés triunfó sobre el liberalismo británico, Robespierre sobre Locke, y con ello hubieron de naufragar para siempre instituciones y fueros tradicionales que, correctamente interpretados, podrían representar la propia tradición liberal de los Reinos y nacionalidades de España.

\section{FUENTES Y BIBLIOGRAFÍA}

ALVAREZ JUNCO, J. [2001]: Mater dolorosa. Madrid, Taurus.

CARANTOÑA ALVAREZ, F. [1989]: Revolución liberal y crisis de las instituciones tradicionales asturianas. Gijón, Silverio Cañada.

CAVEDA Y NAVA, J. y OTROS [1989]: La Junta General del Principado. Gijón, Silverio Cañada.

FOX, I. [1997]: La invención de España. Madrid, Cátedra.

HOBSBAWM, E. [1991]: Naciones y nacionalismo desde 1780. Barcelona, Crítica.

TUERO BERTRAND, F. [1978]: La Junta General del Principado de Asturias. Salinas, Ayalga. 